\title{
Increased Risk for ESBL-Producing Bacteria from Co-administration of Loperamide and Antimicrobial Drugs for Travelers' Diarrhea ${ }^{1}$
}

\author{
Anu Kantele, Sointu Mero, \\ Juha Kirveskari, Tinja Lääveri
}

Antimicrobial drug treatment of travelers' diarrhea is known to increase the risk for colonization with extended-spectrum b-lactamase-producing Enterobacteriaceae. Among 288 travelers with travelers' diarrhea, the colonization rate without medications was $21 \%$. For treatment with loperamide only, the rate was $20 \%$; with antimicrobial drugs alone, $40 \%$; and with loperamide and antimicrobial drugs, $71 \%$.

$\mathrm{R}$ esistance to antimicrobial drugs (AMDs) is predisposed in areas with poor hygiene and weak or nonexistent antimicrobial policy. Travelers visiting these areas presumably have a central role as transporters of multidrug-resistant intestinal bacteria across the globe (1), because a significant proportion of travelers $(20 \%-70 \%)$ to high-prevalence areas become colonized with extended-spectrum $\beta$-lactamase-producing Enterobacteriaceae (ESBL-E) (2-7). Clinical infections do not develop in most travelers ( 6 ), and colonization is transient, waning within months (7). However, as evidenced by intrahousehold transmission from colonized patients after hospitalization, the bacteria may spread to household members $(8,9)$ and eventually to local healthcare settings in the home countries of the travelers.

Several factors have been identified to increase the risk for ESBL-E colonization: travel destination (2-7), travelers' diarrhea (TD) $(2,6,7)$, use of AMDs (5-7), and age $(2,6)$. In a recent study, we found that ESBL-E was contracted by $11 \%$ of travelers who did not have TD and did not take AMDs (TD-AMD-), 21\% of those with TD who did not take AMDs (TD+AMD-), and $37 \%$ of those with TD who took AMDs (TD+AMD+) (6). Our conclusion that mild or moderate diarrhea should not be treated with AMDs raised questions about safe alternatives (10). In our previous study, probiotics appeared not to affect

Author affiliations: Medical Centre Aava, Helsinki (A. Kantele); Karolinska Institutet, Solna, Stockholm, Sweden (A. Kantele); University of Helsinki, Helsinki, Finland (A. Kantele, T. Lääveri); Helsinki University Hospital (A. Kantele, T. Lääveri); Helsinki University Hospital Laboratory, Helsinki (S. Mero, J. Kirveskari)

DOI: http://dx.doi.org/10.3201/eid2201.151272 colonization (6). We found no studies that assessed possible risks posed by non-AMD antidiarrheal medications for treating TD, such as loperamide.

Loperamide, a drug with both antisecretory and antimotility effects (11), is widely used by travelers (12). Although mostly used alone, loperamide is sometimes used with AMDs; the combination stops symptoms faster than AMDs alone during the first 2 days of TD. After that, the combination no longer appears advantageous, probably because symptoms resolve naturally (11). Using loperamide with AMDs is presented as a safe option in general guidelines published by the US Centers for Disease Control and Prevention (13). However, the effects of co-administration on the risk for ESBL-E acquisition have not been addressed.

Some researchers have posed the question as to whether the antimotility effect of loperamide, involving prolonged passage through the gastrointestinal tract, would, in fact, increase the risk for colonization (data not shown). Such speculations prompted us to revisit our recent data (6) to compare loperamide, AMDs, and their combination in the treatment of TD with regard to the risk for contracting travel-acquired ESBL-E.

\section{The Study}

We reviewed our recent data on ESBL-E acquisition among 430 travelers from Finland (6), selecting those with TD for separate analysis (Figure). All the volunteers provided fecal samples and completed questionnaires before and after travel. Symptoms of TD and use of medications, such as loperamide and AMDs, were included in the posttravel questionnaires. The countries visited were grouped as described (Table 1; 6); processing of fecal specimens and identification of ESBL-E were detailed in our previous study (6). TD was defined by the World Health Organization criteria: passing $\geq 3$ loose/liquid stools per 24 hours, or more frequently than normal (14).

Study participants were divided into 4 groups by treatment of TD: those taking no loperamide or AMDs (LOAMD-); only loperamide (LO+AMD-); only AMDs (LO$\mathrm{AMD}+$ ); or loperamide plus AMDs (LO+AMD+). Those having taken AMDs for non-TD indications were categorized in groups with those with TD who took AMDs.

${ }^{1}$ Preliminary results from this study were presented at the 13th Conference of the International Society of Travel Medicine (CISTM), May 24-28, 2015, Quebec City, Quebec, Canada. 


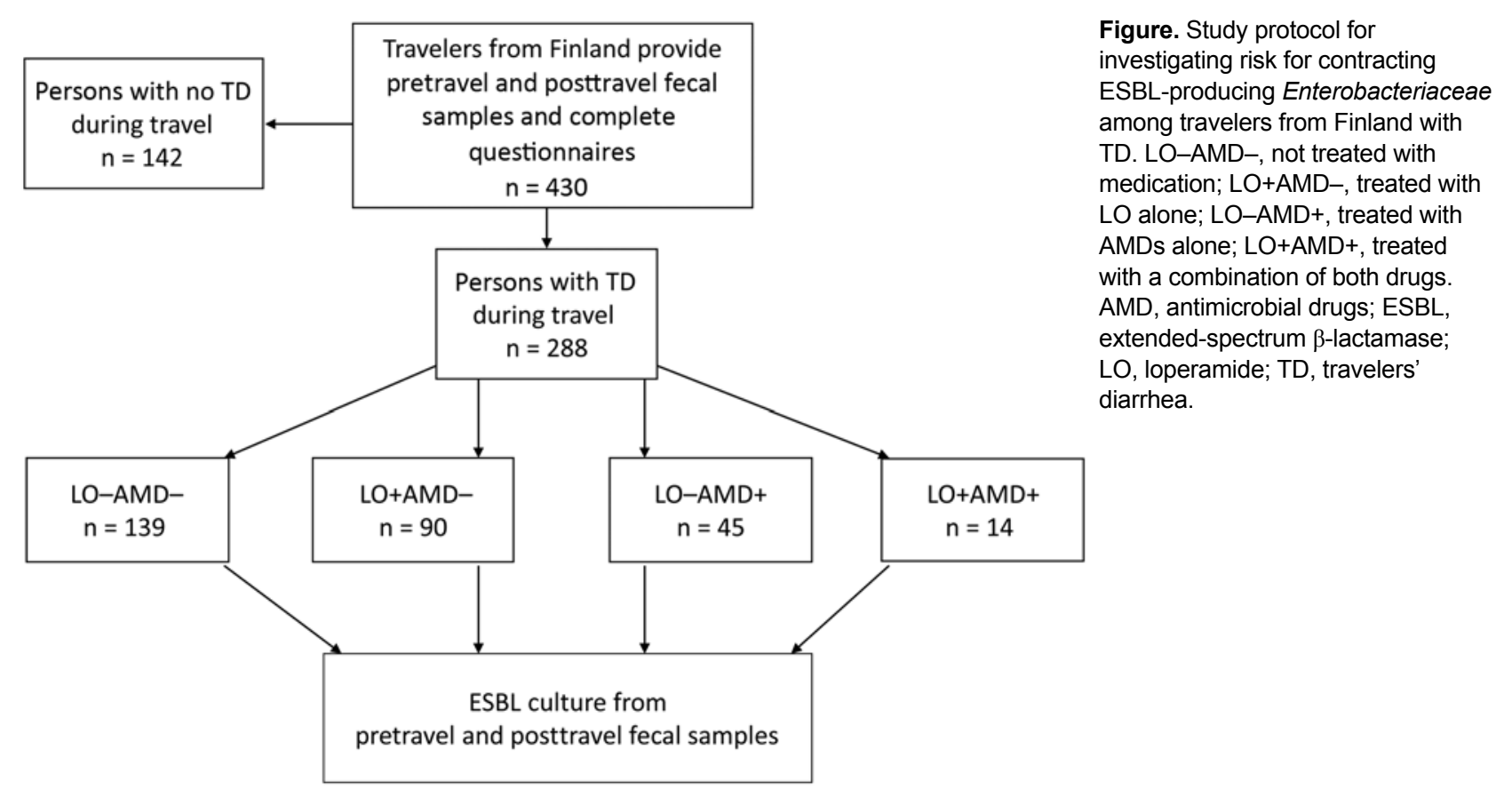

We used a multivariable binary logistic regression model to test our main hypotheses. Loperamide, AMDs, and their interaction (effect modification) were included in the model, along with risk factors that showed a $p$ value $<0.2$ in univariate analysis in our previous study (6): sex, travel destination, use of AMDs, meals with residents of the location, contact with local healthcare, sites of meals, accommodations, duration of travel, age, and use of alcohol. Variables were eliminated to the final model by using backward selection of factors by Akaike Information Criteria, except for loperamide and the use of AMDs and their interaction, which were forced to the final model. Missing values were taken into account by multiple imputations, to reduce possible biases and efficiency loss, assuming that data were missing at random. We analyzed statistics using SPSS statistical software version 21 (IBM Corporation, Armonk, NY, USA).
Of all travelers in the previous study (6), a total of 288 of $430(67 \%)$ who reported TD constituted the final study group (Table 1). ESBL-E was contracted by $26 \%$ of the subjects: $21 \%$ in the LO-AMD- group; $20 \%$ in the LO+AMD - group (adjusted odds ratio [aOR] 0.8, 95\% CI $0.4-1.7$ ); $40 \%$ in the AMD+LO- group (aOR 2.9, 95\% CI $1.2-7.4$ ); and $71 \%$ in the LO+AMD+ group (aOR 7.4, 95\% CI 1.7-32.6) (Table 2). aOR for the interaction term of loperamide and AMDs was 3.1 (95\% CI 0.6-16.6). Travel destination remained an independent risk factor, and sharing meals with locals appeared protective (Table 2).

Studies showing AMD treatment of patients with TD to be an independent risk factor for contracting ESBLE (5-7) have evoked the question of less harmful treatments. The recommendation to restrict AMDs to severe cases $(5,6,15)$ seems reasonable, as TD generally remains

\begin{tabular}{|c|c|c|c|c|c|}
\hline Characteristics & Total no. (\%) & $\begin{array}{c}\text { LO-AMD- } \\
\text { no. }(\%)\end{array}$ & $\begin{array}{c}\text { LO+AMD- } \\
\text { no. }(\%)\end{array}$ & $\begin{array}{c}\text { LO-AMD+ } \\
\text { no. }(\%)\end{array}$ & $\begin{array}{c}\text { LO+AMD+ } \\
\text { no. }(\%)\end{array}$ \\
\hline Total & 288 & $139(48)$ & $90(31)$ & $45(16)$ & $14(5)$ \\
\hline \multicolumn{6}{|l|}{ Sex } \\
\hline $\mathrm{F}$ & $180(62)$ & $86(62)$ & $54(60)$ & $32(71)$ & $8(57)$ \\
\hline$M$ & $108(38)$ & $53(38)$ & $36(40)$ & $13(29)$ & $6(43)$ \\
\hline Age, y, median (IQR) & $34(25)$ & $34(26)$ & $34(23)$ & $35(24)$ & $31(38)$ \\
\hline \multicolumn{6}{|l|}{ Geographic region } \\
\hline South Asia & $46(16)$ & $19(14)$ & $17(19)$ & $5(11)$ & $5(36)$ \\
\hline Southeast Asia & $78(27)$ & 41 (29) & $24(27)$ & $10(22)$ & $3(21)$ \\
\hline East Asia & $4(1)$ & $1(1)$ & $1(1)$ & $2(4)$ & $0(0)^{\prime}$ \\
\hline Sub-Saharan Africa & $130(45)$ & $62(45)$ & $39(43)$ & $23(51)$ & $6(43)$ \\
\hline North Africa and Middle East & $5(2)$ & $3(2)$ & $1(1)$ & $1(2)$ & $0(0)$ \\
\hline South and Central America and the Caribbean & $23(8)$ & $12(9)$ & $7(8)$ & $4(9)$ & $0(0)$ \\
\hline Europe and North America & $2(1)$ & $1(1)$ & $1(1)$ & $0(0)$ & $0(0)$ \\
\hline
\end{tabular}


Table 2. Multivariable analysis of acquisition of extended-spectrum $\beta$-lactamase-producing Enterobacteriaceae by 288 travelers on the basis of administration of treatments for travelers' diarrhea* $\dagger$

\begin{tabular}{|c|c|c|c|c|c|c|c|}
\hline \multirow[b]{2}{*}{ Characteristics } & \multirow{2}{*}{$\begin{array}{l}\text { Total, no. } \\
(\%)\end{array}$} & \multirow{2}{*}{$\begin{array}{c}\text { ESBL } \\
\text { neg, no. } \\
(\%)\end{array}$} & \multirow{2}{*}{$\begin{array}{l}\text { ESBL pos, } \\
\text { no. }(\%)\end{array}$} & \multicolumn{2}{|c|}{ Univariate analysis } & \multicolumn{2}{|c|}{$\begin{array}{l}\text { Multivariable analysis with } \\
\text { imputation }\end{array}$} \\
\hline & & & & $\mathrm{p}$ value & OR $(95 \% \mathrm{Cl})$ & $p$ value & aOR $(95 \% \mathrm{Cl})$ \\
\hline Total & $288(100)$ & $213(74)$ & $75(26)$ & NA & NA & NA & NA \\
\hline \multicolumn{8}{|l|}{ Study groups } \\
\hline LO-AMD- & 139 (48) & $110(79)$ & $29(21)$ & NA & 1.0 & NA & \\
\hline LO+AMD- & $90(31)$ & $72(80)$ & $18(20)$ & 0.874 & $0.9(0.5$ & 0.583 & $0.8(0.4-1.7)$ \\
\hline LO-AMD+‡ & 45 (16) & $27(60)$ & $18(40)$ & 0.012 & $1.2-5$ & 0.022 & $2.9(1.2-7.4)$ \\
\hline LO+AMD+ & 14 & $4(29)$ & & & 4) & 0.008 & $7.4(1.7-32.6) \S$ \\
\hline \multicolumn{8}{|l|}{ Travel destination } \\
\hline South Asia & $46(16)$ & $21(46)$ & $25(54)$ & NA & 1.0 & NA & 1.0 \\
\hline t Asia & $78(27)$ & $48(62)$ & 30( & 0.087 & $(0)$. & 0.186 & $0.6(0.3-$ \\
\hline Eas & $4(1)$ & $2(50)$ & $2(50)$ & 0.867 & ) & 0.989 & $(0.1-12.3)$ \\
\hline haran Africa & $130(45)$ & $114(88)$ & $16(12)$ & $<0.001$ & $(0.1-c$ & $<0.001$ & $0.1(0.05-0.3)$ \\
\hline North Africa and Middle East & $5(2)$ & $3(60)$ & $2(40)$ & 0.546 & $0.6(0.1-6.7)$ & 0.536 & $0.5(0.1-3.8)$ \\
\hline $\begin{array}{l}\text { South and Central America and } \\
\text { the Caribbean }\end{array}$ & $23(8)$ & $23(100)$ & 0 & NA & NA & NA & NA \\
\hline Europe and North America & $2(1)$ & $2(100)$ & 0 & NA & $\mathrm{N} /$ & NA & NA \\
\hline \multicolumn{8}{|l|}{ Other factors } \\
\hline Sharing meals & $52(19)$ & $46(88)$ & & & & 0.017 & 0.1 \\
\hline Contact with local healthcare & $32(11)$ & $18(56)$ & $14(44)$ & $<0.001$ & $2.5(1.2-5.3)$ & 0.314 & $1.7(0.6-4.7)$ \\
\hline \multicolumn{8}{|c|}{$\begin{array}{l}\text { *ESBL, extended-spectrum } \beta \text {-lactamase; OR, odds ratio; aOR, adjusted odds ratio; LO, loperamide; AMD, antimicrobial drugs; LO-AMD-,not treated with } \\
\text { medication; LO+AMD-, treated with LO alone; LO-AMD+, treated with AMDs alone; LO+AMD+, treated with a combination of both drugs; NA, not } \\
\text { applicable; pos, positive; neg, negative. } \\
\text { tValues represent proportions with a given risk factor, aOR and p values in univariate and multivariable analysis. By using backward selection of factors } \\
\text { by Akaike Information Criteria, the following factors were eliminated of the variables in the final model: age, duration of travel, sex, alcohol, site of meals, } \\
\text { and type of accommodation. } \\
\text { fIncludes } 7 \text { travelers having taken antimicrobial drugs for indications other than TD. } \\
\text { §aOR for interaction term of loperamide and AMDs is } 3.1(95 \% \mathrm{Cl} 0.6-16.6) \text {. } \\
\text { TInformation missing for } 18 \text { travelers. }\end{array}$} \\
\hline
\end{tabular}

mild or moderate and resolves spontaneously $(12,15)$. If symptoms require medical treatment, loperamide appears to be a sensible alternative for travelers who have no fever or bloody stools. However, because of its antimotility effect, its safety against contracting resistant intestinal bacteria has been questioned. Among studies that explored risk factors for ESBL carriage, we found none that showed data on the use of loperamide alone or in combination with AMDs.

Consistent with our previous analysis (6), we found AMD treatment of TD was an independent risk factor for colonization with ESBL-E; the rate increased from $21 \%$ (LO-AB-) to $40 \%$ (LO-AB+) (aOR 2.9, 95\% CI 1.2-7.4). When used alone, loperamide did not add to the risk $(20 \%$ colonized in the $\mathrm{LO}+\mathrm{AB}-$ group).

In the group taking both loperamide and AMDs, the colonization rate was strikingly high, increasing from $21 \%$ ( $\mathrm{LO}-\mathrm{AB}-)$ to $71 \%(\mathrm{LO}+\mathrm{AB}+)$. The rate also appeared to exceed the risk for using AMDs alone (40\%), yet the interaction term of loperamide and AMDs did not reach statistical significance (aOR 3.1, 95\% CI 0.6-16.6), and the small subject number resulted in wide CIs. Theoretically, an additional increase in the risk seen in the combination group could be brought about by loperamide: because of its antimotility effect, contact time of the AMD to the gut lumen is increased, and the selection pressure posed by the AMD may be prolonged, thus intensifying its unfavorable effects.
Our study design was limited by not including a randomized allocation of therapy and the varied use of loperamide according to symptoms. However, no association was seen between the severity of symptoms and acquisition of ESBL-E (data not shown).

Studies are needed to compare the relative risk posed by various AMD classes. Exploration of the influence of nonantimicrobial antidiarrheal agents with only antisecretory effect, such as racecadotril, as monotherapy and in combination with AMDs would also be beneficial.

\section{Conclusions}

Our results show that loperamide alone offers a safe alternative to AMDs for TD treatment, because it does not add to the risk for acquiring drug-resistant intestinal bacteria. In contrast, combining loperamide with AMDs predisposes to ESBL-E colonization and may add to the substantial risk posed by AMDs alone. Our data dispute the safety of this combination.

\section{Acknowledgments}

We express our gratitude to Jukka Riutta (deceased) for recruiting the patients. We also thank the nurses at the Travel Clinic of Aava Medical Centre for help in recruiting the volunteers, the personnel of Helsinki University Hospital Laboratory for processing the stool specimens and Jukka Ollgren for expert advice in statistical analyses. 
The work was supported by the Finnish Governmental Subsidy for Health Science Research and by the Scandinavian Society for Antimicrobial Chemotherapy Foundation. The funding sources had no involvement in study design, collection, analysis and interpretation of data, devising manuscript, and decision to submit the article for publication.

Dr. Kantele is an associate professor and senior lecturer at the University of Helsinki, Finland; visiting professor at the Karolinska Institute, Sweden; and an Infectious Diseases Consultant at Helsinki University Hospital. Her research interests include aspects of infectious diseases, including global health, travelers' health, tropical diseases, antimicrobial resistance, diarrheal pathogens, vaccinations, and infection immunology.

\section{References}

1. Kantele A. As far as travelers' risk of acquiring resistant intestinal microbes is considered, no antibiotics (absorbable or nonabsorbable) are safe. Clin Infect Dis. 2015;60:1872-3. http://dx.doi.org/10.1093/cid/civ174

2. Östholm-Balkhed A, Tärnberg M, Nilsson M, Nilsson LE, Hanberger H, Hällgren A; Travel Study Group of Southeast Sweden. Travel-associated faecal colonization with ESBLproducing Enterobacteriaceae: incidence and risk factors. J Antimicrob Chemother. 2013;68:2144-53. http://dx.doi.org/ 10.1093/jac/dkt167

3. Paltansing S, Vlot JA, Kraakman ME, Mesman R, Bruijning ML, Bernards AT, et al. Extended-spectrum $\beta$-lactamase-producing Enterobacteriaceae among travelers from the Netherlands. Emerg Infect Dis. 2013;19:1206-13. http://dx.doi.org/10.3201/ eid1908.130257

4. Kuenzli E, Jaeger VK, Frei R, Neumayr A, DeCrom S, Haller S, et al. High colonization rates of extended-spectrum $\beta$-lactamase (ESBL)-producing Escherichia coli in Swiss travellers to South Asia - a prospective observational multicentre cohort study looking at epidemiology, microbiology and risk factors. BMC Infect Dis. 2014;14:528. http://dx.doi.org/10.1186/1471-2334-14-528

5. Angelin M, Forsell J, Granlund M, Evengard B, Palmgren H, Johansson A. Risk factors for colonization with extended-spectrum beta-lactamase producing Enterobacteriaceae in healthcare students on clinical assignment abroad: A prospective study. Travel Med Infect Dis. 2015;13:223-9. http://dx.doi.org/10.1016/ j.tmaid.2015.04.007
6. Kantele A, Lääveri T, Mero S, Vilkman K, Pakkanen SH, Ollgren J, et al. Antimicrobials increase the risk of ESBL-PE colonization in travelers. Clin Infect Dis. 2015;60:837-46. http://dx.doi.org/10.1093/cid/ciu957

7. Ruppé E, Armand-Lefèvre L, Estellat C, Consigny PH, El Mniai A, Boussadia Y, et al. High rate acquisition but short duration of carriage of multidrug-resistant Enterocateriaceae after travel to the tropics. Clin Infect Dis. 2015;61:593-600. http://dx.doi.org/10.1093/cid/civ333

8. Valverde A, Grill F, Coque TM, Pintado V, Baquero F, Cantón R, et al. High rate of intestinal colonization with extended-spectrum$\beta$-lactamase-producing organisms in household contacts of infected community patients. J Clin Microbiol. 2008;46:2796-9. http://dx.doi.org/10.1128/JCM.01008-08

9. Hilty M, Betsch BY, Bögli-Stuber K, Heiniger N, Stadler M, Küffer M, et al. Transmission dynamics of extended-spectrum $\beta$-lactamase-producing Enterobacteriaceae in the tertiary care hospital and the household setting. Clin Infect Dis. 2012;55:967-75. http://dx.doi.org/10.1093/cid/cis581

10. Connor BA, Keystone J. Antibiotic self-treatment of travelers' diarrhea: helpful or harmful? Clin Infect Dis. 2015;60:847-8. http://dx.doi.org/10.1093/cid/ciu961

11. Riddle MS, Arnold S, Tribble DR. Effect of adjunctive loperamide in combination with antibiotics on treatment outcomes in traveler's diarrhea: a systematic review and meta-analysis. Clin Infect Dis. 2008;47:1007-14. http://dx.doi.org/10.1086/591703

12. Pitzurra R, Steffen R, Tschopp A, Mutsch M. Diarrhoea in a large prospective cohort of European travellers to resourcelimited destinations. BMC Infect Dis. 2010;10:231. http://dx.doi.org/10.1186/1471-2334-10-231

13. Connor BA. Travelers' diarrhea. In: Centers for Disease Control and Prevention. CDC health information for international travel 2016. New York: Oxford University Press; 2016 [cited 2015 Jul 28]. http://wwwnc.cdc.gov/travel/yellowbook/2014/ chapter-2-the-pre-travel-consultation/travelers-diarrhea

14. World Health Organization. Health topics: Diarrhoea [cited 2015 July 28] http://www.who.int/topics/diarrhoea/en

15. Belderok SM, van den Hoek A, Kint JA, Schim van der Loeff MF, Sonder GJ. Incidence, risk factors and treatment of diarrhoea among Dutch travellers: reasons not to routinely prescribe antibiotics. BMC Infect Dis. 2011;11:295. http://dx.doi.org/ 10.1186/1471-2334-11-295

Address for correspondence: Anu Kantele, Clinic of Infectious Diseases, Inflammation Center, Helsinki University Hospital, PO Box 348, Helinski, FI-00029 HUS, Finland; email: anu.kantele@hus.fi

\section{The Past Is Never Dead- Measles Epidemic, Boston, Massachusetts, 1713}

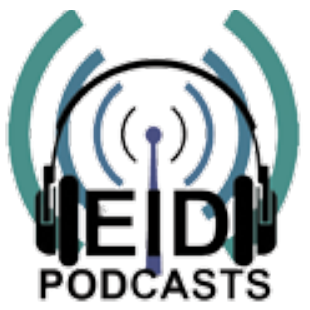

$$
\begin{aligned}
& \text { Dr. David Morens reads excerpts from his } \\
& \text { essay about Cotton Mather's diary, } \\
& \text { which details the experience and tragedy } \\
& \text { of the measles outbreak in } \\
& \text { Boston, Massachusetts, in 1713. }
\end{aligned}
$$

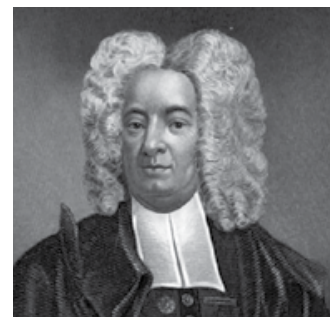

http://www2c.cdc.gov/podcasts/player.asp?f=8638047 